\title{
MODELAGEM DE TRAJETÓRIAS DE CAPACITAÇÃO E EXPERIÊNCIAS DOS EDUCADORES INCLUSIVOS: INSTRUMENTALIZANDO A GESTÃO DE SISTEMAS EDUCACIONAIS
}

\section{ARTIGO ORIGINAL}

SANTOS, José Arthur da Silva ${ }^{1}$

LIMA, Wagner Soares de ${ }^{2}$

SANTOS, José Arthur da Silva. LIMA, Wagner Soares de. Modelagem de trajetórias de capacitação e experiências dos educadores inclusivos: instrumentalizando a gestão de sistemas educacionais. Revista Científica Multidisciplinar Núcleo do Conhecimento. Ano 04, Ed. 10, Vol. 03, pp. 98-108. Outubro de 2019. ISSN: 24480959, Link de

acesso: https://www.nucleodoconhecimento.com.br/educacao/modelagem-de$\underline{\text { trajetorias }}$

\section{RESUMO}

Ao fazer um exercício reflexivo e visualizar a sala de aula do Ensino Médio, na qual esteja um aluno Surdo, portanto, com necessidades especiais educacionais (NEE), incluído entre os demais alunos ouvintes, observar-se-á um contexto específico e sujeitos que carecem de um acervo preparatório para atuarem satisfatoriamente.

1 Especialista em Metodologia do Ensino de Biologia e Química, Tecnólogo de Sistemas Elétricos pelo Instituto Federal (IFAL). Graduando em Licenciatura em Química pela Universidade Federal de Alagoas (UFAL). Aluno especial do Mestrado em Educação, Culturas e Identidades (UFRPE).

${ }^{2}$ Mestre em Ecologia Humana e Gestão Socioambiental (UNEB), Especialista em Gestão Pública (UFAL), pós-graduando em Psicologia Junguiana (IDE), Bacharel em Administração (UFAL), Graduado em Segurança pública (PMAL). Aluno especial do doutorado em geografia (UFPE) e saúde pública (FIOCRUZ). 
Numa perspectiva da gestão de carreira, usando uma metodologia de modelagem de processos e após uma revisão da literatura pertinente, o presente trabalho pretende identificar quais experiências são essas que habilitam (ou não) o professor regente e o tradutor/intérprete de Libras (TIL) a manterem uma comunicação fluída junto ao adolescente com NEE. Por fim, propõe-se quais mudanças na formação inicial (e, portanto, nos cursos de Licenciatura) ou na seleção dos profissionais pode influenciar na melhoria das condições de funcionamento do sistema educacional, verdadeiramente, inclusivo.

Palavras-chave: Administração Pública, professor regente, Tradutor/Intérprete.

\section{INTRODUÇÃO}

Com o processo de redemocratização ocorrido na década de 1980, "a educação para todos", passou a ser discutida no país de forma mais acentuada por fortes organizações da população na luta pelo reconhecimento e institucionalização dos seus direitos. Para o autor Simões (2009, p.341), nesse período, "os direitos de cidadania, nesse campo (no que se refere às pessoas com deficiência), visando, sobretudo, à inclusão social, formularam-se, de forma sistemática".

O processo de inclusão é algo que vem sendo discutido por grandes teóricos e pesquisadores da área de educação tanto no âmbito municipal, estadual e federal tendo como decorrências as políticas de ações afirmativas que coberta o acesso e permanência daquelas pessoas excluídas do sistema de ensino.

Atender alunos com necessidades educacionais especiais (NEE), dentro da abordagem inclusiva, requer da escola regular um alto nível de adaptação, dentre vários fatores, a qualificação humana dos agentes envolvidos no processo de ensinoaprendizagem é particularmente relevante. Quando a NEE é decorrente da presença da surdez, dois são os profissionais diretamente ligados ao contexto da sala de aula, na qual está incluído o aluno surdo: (a) o professor regente e o (b) tradutor/intérprete de língua de sinais (TIL). 
Esse específico ambiente de contexto (conforme a Figura 1) conta ainda com a presença de mais duas categorias de sujeitos: (c) os alunos surdos e (d) os alunos ouvintes. Assim sendo, professores, intérpretes e alunos possuem cada um sua própria história de formação, capacitação e experiência do cotidiano que os tornam mais ou menos preparados para desempenhar o papel social esperado deles dentro da sala de aula.

Figura 1: Sujeitos do ambiente de contexto: sala de aula de escola regular com surdo incluído.

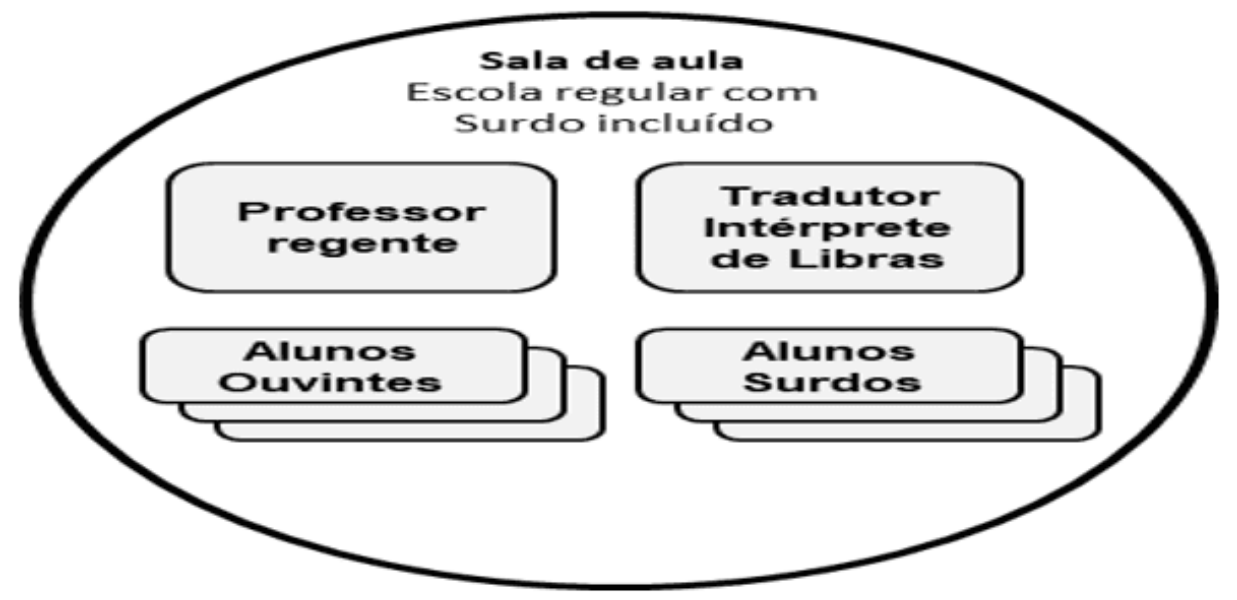

Fonte: Elaborado pelos Autores

A presente abordagem pode ser considerada pouco usual, pois não se trata em si de um estudo em Educação Inclusiva das Ciências da Educação, mas de uma proposta da Gestão de sistemas escolares servindo aos propósitos da inclusão e, portanto, apesar da patente interdisciplinaridade, guarda uma aderência inicial ao campo da Administração Pública e da formulação de Políticas Públicas.

A teleconferência permite ao indivíduo participar de um encontro nacional ou regional sema necessidade de deixar seu local de origem. Tipos comuns de teleconferências incluem o uso da televisão, telefone e computador. Através de áudio-conferência, utilizando a companhia local de telefone, um sinal de áudio pode ser emitido em um salão de qualquer dimensão (NICHOLS, 1993, p.181). 


\section{OBJETIVO}

O presente esforço acadêmico pretende identificar quais experiências são essas do professor regente e do TIL que os habilitam (ou não) a manter uma comunicação fluída junto a esse adolescente com NEE. Por fim, propõe-se quais mudanças na formação inicial ou na seleção dos profissionais pode influenciar na melhora das condições de funcionamento do sistema escolar, verdadeiramente, inclusivo.

\section{FUNDAMENTAÇÃO}

Faz-se uso do que foi expresso por Carvalho (2004), para demonstrar o que normalmente se esperar de mudanças para efetivar uma prática inclusiva na escola: (1) valorização profissional dos professores, (2) aperfeiçoamento das escolas e do pessoal docente; (3) utilização dos professores das classes especiais; (4) trabalho em equipe e (5) adaptações curriculares.

Cabe observar que cada uma das ações elencadas não estão apenas sob a responsabilidade do docente que se fará presente junto ao aluno incluído. Questões como adaptação de currículo dependem em muitos casos da interação entre os partícipes do sistema educacional e suas várias instâncias.

Uma nova demanda de prática docente na escola acabará por exigir, não apenas a mudança do currículo da Educação Básica, mas tanto quanto no Ensino Superior, contexto de onde provém esse docente. Na condição de estudante de licenciatura, o futuro docente está sob a tutela formativa da Universidade. Assim sendo, a repetida sentença que enseja um alto nível de adaptação da Escola, deve se estender à Universidade, que precisa está disposta a promover mudanças em suas dinâmicas internas tanto quanto se cobra da Escola.

Outros elementos que caminham para a construção da educação realmente inclusiva, perpassam por questões, pro vezes, alheias ao docente. Contratação de demais funcionários da escola que estejam preparados para transpor as barreiras atitudinais é essencial; a licitação de obras e reformas na infraestrutura física para dissolver 
barreiras físicas é outro exemplo de questões interdependentes, que fazem a inclusão não depender apenas dos esforçados e engajados profissionais da educação propriamente ditos.

Quando se trata de educação inclusiva, muito se fala sobre novos paradigmas na prática docente e, realmente, é o foco deste trabalho as dinâmica dentro da sala de aula, onde há um aluno com NEE incluído. Porém, sem sensibilizar o gestor escolar os esforços do engajamento docente na causa serão inócuo. Assim como nos informa Sant'Ana (2005) de que, em meio a uma orientação que realmente se queira denominar inclusiva, às funções do gestor escolar acrescentam-se: (1) definir os objetivos da instituição; (2) estimular a capacitação dos professores; (3) promover às trocas e interações e (4) fortalecer o apoio a processos compatíveis com a filosofia desejada.

Para tanto não basta ser sensibilizado a querer, precisar saber fazê-lo. E, ainda que o gestor escolar se mobilize em atitude proativa em direção à causa da inclusão, sem que tenha as competências administrativas necessárias e sem que o sistema educacional abarcador tenha em si, as estruturas propícias para as dinâmicas de adaptabilidade e humanização, todo o esforço será sempre um componente que intensificará a sensação de frustração.

Portanto, para além do docente na sala, para além do gestor da unidade escolar, os sistemas educacionais como um todo precisam de alterações substanciais (SAGE, 1999). Essa compreensão fica mais bem expressa, por Dutra e Griboski.

A gestão para inclusão pressupõe um trabalho competente, à luz de um paradigma dinâmico, mobilizador da sociedade e responsável pela transformação dos sistemas educacionais, contribuindo para melhoria da qualidade do ensino e aprendizagem e apontando respostas para aqueles grupos que têm sido mais excluídos do processo educacional. (DUTRA e GRIBOSKI, 2005, p. 13).

Sofia Lercher Vieira (2007, p.56), esclarece que "no plano mais concreto dos sistemas educacionais, as políticas contribuem tanto a reproduzir uma ordem estabelecida, quanto a transformá-la". Portanto, em um sistema educacional, que é o campo das 
instituições e dos poderes mediados por tais instituições, a política educacional é a orientadora das demais ações pontuais que se desenvolvem no interior desse sistema. Podendo orientar para a concretização de objetivos como a inclusão ou constantemente frustrá-los

Ainda segundo Vieira (2007, p.53), são "as políticas que traduzem as intenções do Poder Público, ao serem transformadas em práticas se materializam na gestão". Por melhores e mais nobres que sejam as intenções de qualquer gestor ou gestora, suas ideais precisam ser viáveis (condições de implementação) e aceitáveis (condições políticas) (VIEIRA, 2007). Compreendendo que a aceitabilidade é uma questão focada na vida política, este trabalho se dispõe a lançar alguma luz sobre a condição de viabilidade.

Mas tal viabilidade não pode apenas está adstrita ao contexto sala de aula, ele é o fim, é o cenário que se materializa todo o esforço e engajamento pretendido, mas em termos de possibilidade de mudanças nos atuais quadros de exclusão, é preciso que soluções sejam tecidas de forma concomitante em uma rede de ações de forma sistêmica (LÜCK, 2017).

\section{METODOLOGIA}

Após uma combinação de revisão da literatura e uma análise reflexiva, foi feita a modelagem conceitual das trajetórias mais prováveis do (1) professor regente e do (2) TIL. Para a apresentação da síntese reflexiva, foi usado um instrumento típico da área de engenharia da produção em serviços: a modelagem conceitual de processos, o qual é expresso em diagrama de fluxos. Trata-se de uma proposta de pesquisa teórica de cunho qualitativo, de exploração básica que visa subsidiar futuros debates com maior aprofundamento.

Cabe destacar que ambos os autores trazem memórias de experiências vivenciadas em sala de aula em contextos correlatos ao pesquisado: (1) como professor regente em turma de Ensino Médio com surdo incluído na ausência de TIL; (2) como monitor da disciplina de Libras no Ensino Superior Tecnológico para ouvintes, (3) assim como 
servindo de TIL para professor surdo. Portanto, o presente texto constitui-se, além de revisão bibliográfica, um relato de observação participante.

\section{DESCRIÇÃO DA ATIVIDADE/ RESULTADOS E DISCUSSÃO}

Assim como foi estabelecido, a busca pelo que cada sujeito precisa trazer como competência para fluir de forma adequada sua participação nesse contexto, foi reduzida representativamente em dois acervos: (a) a capacitação, que se trata de uma ação sistemática de desenvolvimento de competências, sobretudo, aquelas do componente cognitvo-intelectual e de habilidades técnicas; (b) o acúmulo de experiências vividas em trocas diretas com outros sujeitos, em outros contextos, anteriores ou concomitantes com a atuação, em tela.

Figura 2: Diagrama do modelo geral de análise da trajetória do sujeito.

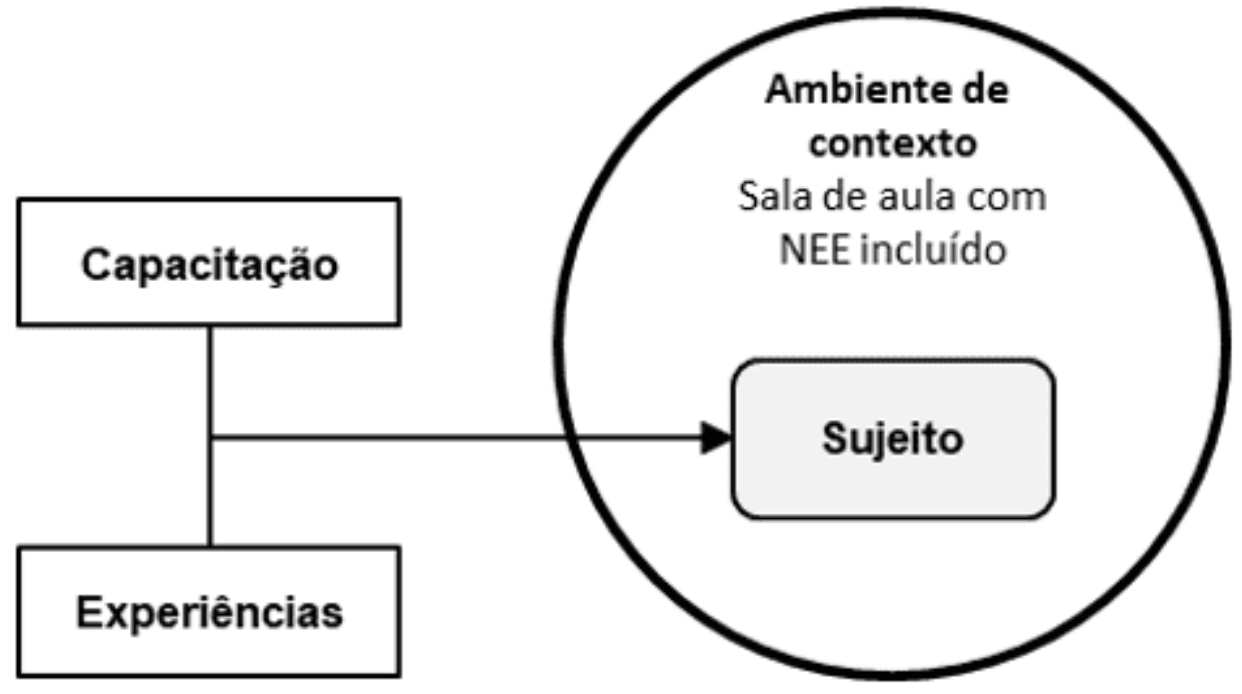

Fonte: Elaborado pelos Autores

O referido esquema, que se apresenta iconograficamente, por não ser capaz de se correlacionar com todos os fatores da complexidade inerente ao tema, pode ser visto na Figura 2. 


\section{PROFESSOR REGENTE}

Algumas exigências por determinadas competências por parte do professor regente, ou seja, o graduado em uma licenciatura específica: i) o professor regente precisa ter proficiência mínima, em Libras, necessária para a convivência com o aluno surdo (não se trata aqui daquela, necessária para lecionar o conteúdo completo tendo a Libras como língua de instrução); ii) demanda qualificação direcionada a como atuar colaborativamente com o TIL, ou seja, metodologia e didática de educação inclusiva (NEE - surdez); iii) dele espera-se que seja sensível ao contexto sociocultural específico do aluno surdo; iv) que tenha noção da legislação pertinente ao tema e v) que consiga desenvolver estratégias localmente orquestradas frente a algum percalço, especialmente, quando da ausência permanente ou momentânea do TIL.

Figura 3: Diagrama de análise da trajetória do professor regente.

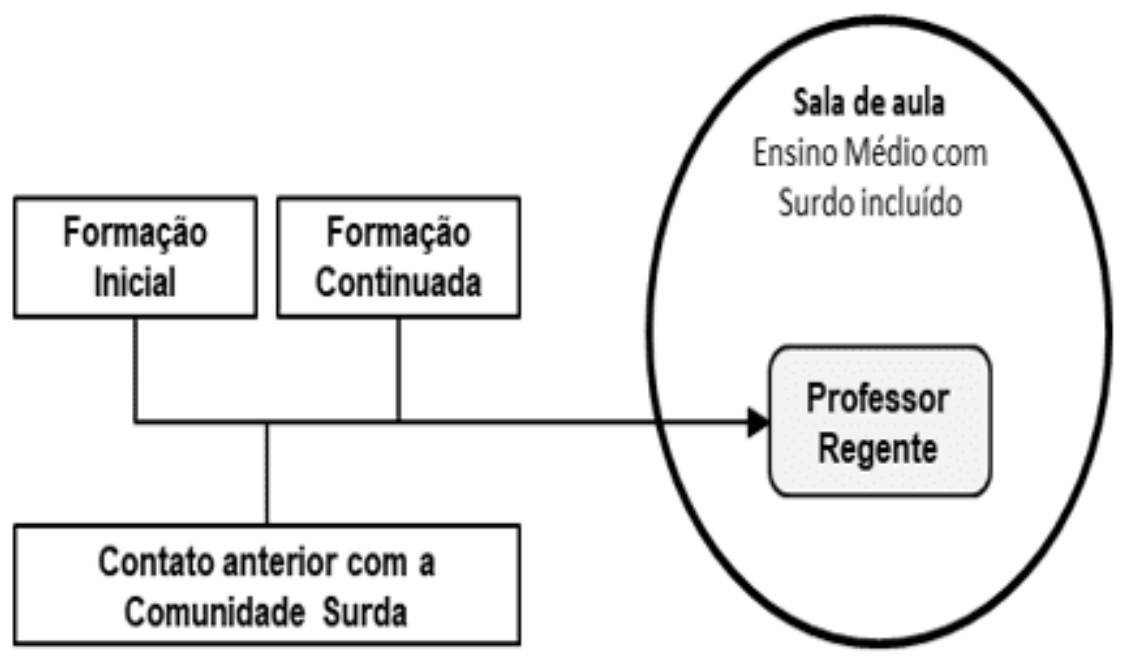

Fonte: Elaborado pelos Autores

Há evidências, sustentadas pela literatura da área, de que a disciplina obrigatória de Libras, conquanto contribua bastante no ambiente de contexto problematizado, ainda não satisfaz os requisitos pertinentes para a atuação do professor regente, outrora egresso de licenciatura (SOARES; SILVA, 2018). Num ou noutro caso, a Universidade ainda é o primaz ambiente promotor, apesar de que na formação inicial existe certo 
tutelamento do graduando e, na formação continuada, é mais evidente o caráter de processo interativo, de formação mútua, de afirmação de valores da profissão, por meio do compartilhamento do conhecimento profissional, que uni a prática a discussões teóricas (NÓVOA, 1999).

\section{TRADUTOR/INTÉRPRETE DE LIBRAS}

Sobre o Tradutor/Intérprete de Libras, o que se pode esperar encontrar na sala com surdo incluso, nas atuais condições vistas no país? i) Um TIL de nível superior, licenciado ou bacharel, supondo um mais preparado que o outro para ambientes educacionais; ii) ou um TIL de nível técnico, o qual pode ele mesmo ter dificuldade com a matéria a ser traduzida; iii) independentemente do nível da formação, um TIL com muita experiência no ambiente escolar; iv) na verdade, pode-se passar pela ausência do TIL, mas com algum aluno ouvinte que entenda o colega surdo; v) o TIL ausente, mas o professor regente minimamente fluente em Libras, o qual se desgastará em revesamento para ora lecionar em Libras, ora lecionar em Língua Portuguesa e vi) e finalmente, não ter TIL disponível e ninguém mais que estabeleça uma comunicação fluida o suficiente para a propagação do conteúdo da aula em língua de sinais.

Figura 4: Diagrama de análise da trajetória do TIL

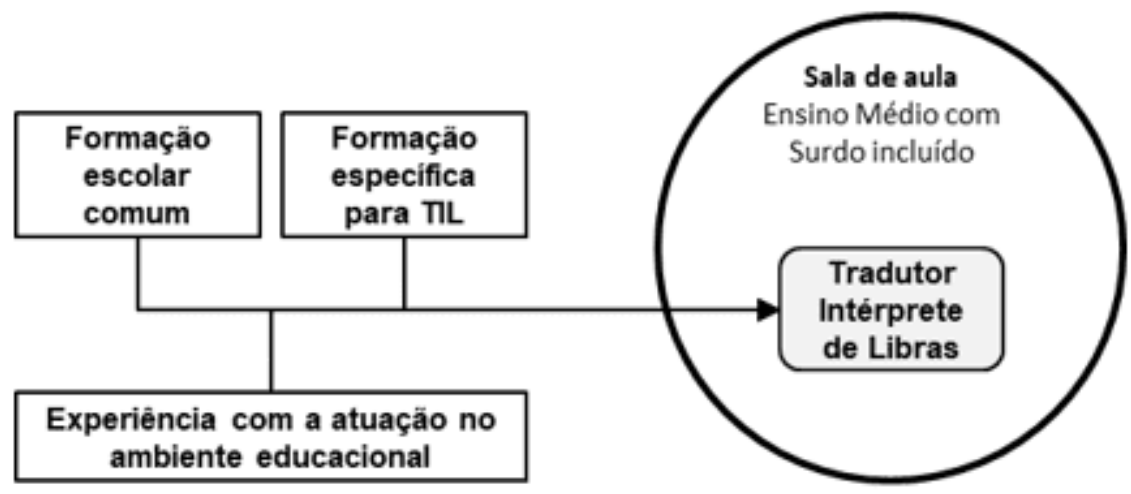

Fonte: Elaborado pelos Autores 


\section{CONSIDERAÇÕES FINAIS}

Conforme a análise feita acima, sintetizam-se a trajetórias e o elementos mínimos de capacitação e acervo de experiências necessárias para atuar junto ao aluno surdo como se vê na Figura 5.

Conclui-se que para (1) professor regente estar mais bem preparado para esse desafio particular, (1a) a Universidade precisa alterar algumas bases das configurações dos cursos de licenciaturas específicas e o (1b) profissional licenciado prevenido sobre a responsabilidade de atuar junto a um aluno com NEE (neste caso a surdez), devendo ser capacitado pela rede de ensino em uma maior qualificação posterior à graduação inicial. (1c) Uma formação inicial específica para o educador inclusivo, uma habilitação diferenciada dentro da Licenciatura, ou a exigência de uma pós-graduação podem ser alternativas viáveis.

Figura 5: Diagrama de análise da trajetória do professor regente e o TIL

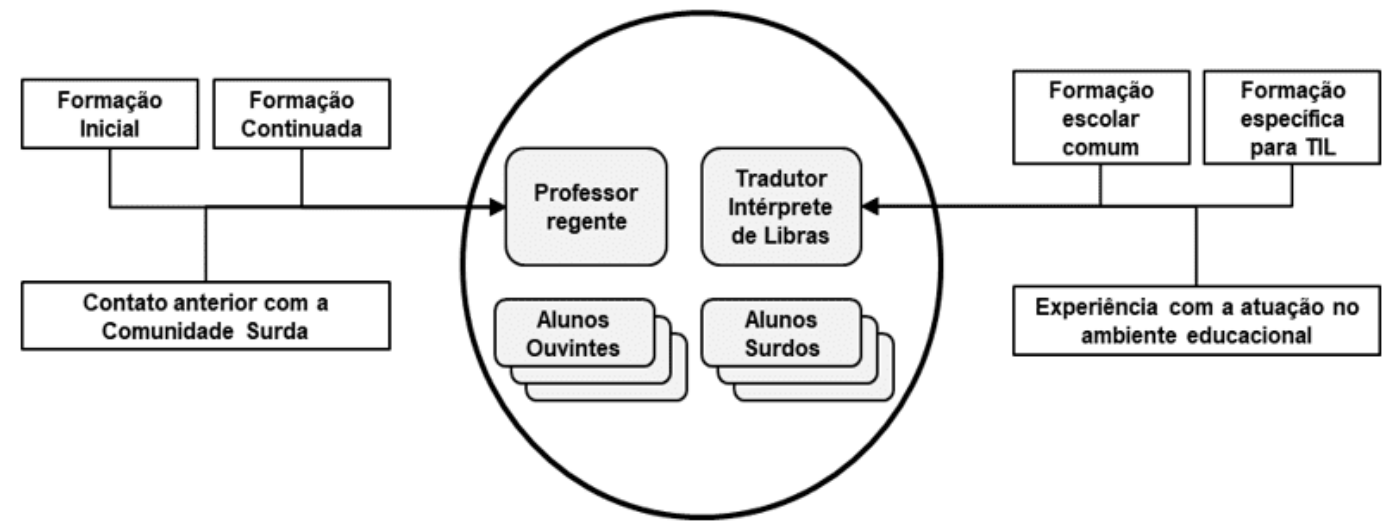

Fonte: Elaborado pelos Autores

Quanto ao TIL, (2) existe uma preocupação inerente ao processo de contratação do profissional que deve recrutar aquele que já tenha experiência no ambiente educacional, (2a) a seleção de profissionais de nível técnico é um tema que mereça debate e (2b) a formação na modalidade de licenciatura no curso de Letras-Libras pode ser preferível a do bacharel. 


\section{REFERÊNCIAS}

CARVALHO, Rosita Edler. Educação inclusiva: com os pingos nos "is". Porto Alegre: Mediação, 2004.

GUBA, E. G.; LINCOLN, Y. S. Fourth generation evaluation. Newbury Park, London, New Delhi: Sage, 1989.

HOFFMAN, J. Avaliação mediadora: uma prática em construção da pré-escola à universidade. Porto Alegre: Mediação, 2001.

LIMA, K. S. Compreendendo as concepções de avaliação de professores de física através da teoria dos construtos pessoais. Recife, 2008. 163 p. Dissertação (Ensino das Ciências). Departamento de Educação, UFRPE, 2008.

LÜCK, Heloísa. Gestão educacional: uma questão paradigmática. Petrópolis-RJ: Vozes, 2017.

MARCANTE, Gabriela. A Defasagem na Formação do Tradutor e Intérprete de Libras.(Monografia) Graduação em Letras Libras - Bacharelado. Joinville-SC: Universidade Federal de Santa Catarina, 2018. Disponível em:< https://repositorio.ufsc.br/bitstream/handle/123456789/188396/TCCGabriela\%20Mar cante\%20-\%20Joinville.pdf?sequence=1 >.Acesso: em 10 de maio de 2019.

NARDI, R.; CORTELLA, B. S. C. Formação de professores de Física: das intenções legais ao discurso dos formadores. In: XVI Simpósio Nacional de Ensino de Física, 2005, Rio de Janeiro. Caderno de Resumos. São Paulo - SP: Sociedade Brasileira de Física, 2005. v. 1. p. 175-175, 2005.

NOVOA, A. Profissão professor . Portugal: Porto, 1999.

SAGE, Daniel D. Estratégias administrativas para a realização do ensino inclusivo. In: STAINBACK, Susan; STAINBACK William (Orgs.). Inclusão: um guia para educadores. Porto Alegre: Artes Médicas, 1999. p.129. 
SALES, E. S.; MONTEIRO, I. G. S.; LIMA, K. S. Formação de professor, diretrizes da Educação brasileira para o ensino de Química e Avaliação: saberes docentes essenciais à formação docente. In: VII Colóquio Internacional Educação e Contemporaneidade, 2013, São Cristóvão - SE. Anais do Colóquio Internacional Educação e Contemporaneidade, 2013.

SANTANA, Izabella M. Educação inclusiva: concepções de professores e diretores. Psicologia em Estudo, Maringá, v. 10, n. 2, p. 227-234, maio/ago., 2005.

SIMÕES, Carlos. Curso de Direito do Serviço Social. 3.ed. rev. e atual. São Paulo: Cortez, 2009 (Biblioteca básica de serviço social; v. 3).

VIEIRA, Sofia L. Política(s) e Gestão da Educação Básica: revisitando conceitos simples. Revista Brasileira de Política e Administração da Educação (RBPAE), vol. 23, num. 01, pp. 53-69, jan./abr. 2007.

Enviado: Setembro, 2019.

Aprovado: Outubro, 2019. 